\title{
La Seguridad Social desde la perspectiva de género
}

PATRICIA BARRERA JiMÉNEZ

Universidad Carlos III

doi: https://doi.org/10.20318/femeris.2017.3555

El pasado 17 de octubre de 2016 se celebró en la Universidad Carlos III de Madrid una jornada dirigida por la profesora Eva María Blázquez Agudo en la que diversos ponentes expusieron las particularidades de nuestro sistema de Seguridad Social desde un enfoque de género.

A lo largo de cuatro horas y media, los asistentes pudieron llevar a cabo un viaje revelador acerca de las numerosas trabas que la sociedad heteropatriarcal impone a un gran número de personas, trabas que no siempre son identificables a primera vista. De hecho, en ello reside la importancia de este tipo de jornadas. No es posible eliminar la discriminación si la propia población no conoce el foco del problema y, por ello, es un regalo que varias expertas y expertos levanten ese velo de normalización y tecnicismos que envuelven nuestra normativa para mostrar las desiguales líneas de partida que hay de fondo. Y es que, como dijo al final de la jornada la directora del Instituto de Estudios de Género, "una ciencia sesgada [que obvia el componente de género] no es una ciencia".

Para la inauguración, se pudo contar con la asistencia de la Dra. Gina Magnolia Riaño Barón, Secretaria General de la Organización Iberoamericana de Seguridad Social.

La Dra. Barón ofreció la visión de una Latinoamérica en la cual la normativa de los países ha avanzado hacia el reconocimiento de la igualdad entre hombres y mujeres. Sin embargo, lo cierto es que aún queda un largo camino para la igualdad real: violencia de género, feminicidios, dependencia económica, todo ello está a la orden del día. Y no se trata únicamente de un peor acceso al mercado laboral, sino que la propia configuración del sistema de prestaciones es un obstáculo en sí. Los roles de género dictan que son las mujeres las que han de hacerse cargo de los cuidados familiares, los sectores "feminizados" son menos valorados, los salarios son más reducidos y, por supuesto, las pensiones no tienen en cuenta particularidades como la mayor longevidad de las mujeres (entre otras cosas). Si ello no fuera suficiente, todos estos obstáculos derivan en una mayor dificultad de acceso a los servicios de salud y tratamiento para un colectivo que lo necesita desesperadamente (maternidad, violencia de género, largas jornadas, etc.).

*100294016@alumnos.uc3m.es 
La Organización Iberoamericana, ante esta situación, está llevando a cabo iniciativas para ponerle remedio. Se ha incluido como objetivo la transversalización de la cuestión de género y se están desarrollando programas concretos de formación y sensibilización, estudios, la creación de redes de personas expertas en género, etc.

A partir de ese momento, la jornada se estructuró en cuatro mesas que trataron diversos temas:

- PRIMERA MESA. Seguridad Social y mujer. Situación actual y retos futuros.

- SEGUNDA MESA. Maternidad, paternidad y prestaciones familiares frente a la situación laboral y familiar de las mujeres.

- TERCERA MESA. Análisis de las pensiones y la dependencia desde la perspectiva de género.

- CUARTA MESA. Desempleo y políticas de integración laboral de la mujer.

A continuación, se expondrán las ideas tratadas en cada mesa.

\section{Seguridad Social y mujer. Situación actual y retos futuros}

Dña. Maravillas Espín Sáez (Universidad Autónoma de Madrid): Dña. Maravillas Espín habla del acceso de la mujer al mercado laboral como "una carrera de obstáculos" que se ha complicado aún más con la crisis económica.

Para empezar, la brecha existente en las tasas de empleo y actividad de hombres y mujeres es evidente, además de que, en éstas últimas, se concentra la contratación temporal. Las dificultades de conciliación con la vida familiar llevan a que el emprendimiento sea inferior, sin olvidar el impacto de la maternidad y del cuidado de mayores en la vida laboral de la mujer fruto de la ausencia de corresponsabilidad.

Concluye la ponente reflejando las catastróficas consecuencias de una crisis en la que la figura del trabajador pobre tiene rostro de mujer. Afirma que dicha crisis "se ha gestionado con normas neutras, y la neutralidad en situaciones desiguales genera más desigualdad".

Dña. Cristina Aragón Gómez (Universidad Carlos III de Madrid): la brecha salarial existente desde la perspectiva de género es indiscutible, y se trata de diferencias que no pueden explicarse únicamente a causa del trabajo a tiempo parcial y las obligaciones familiares, pues persisten si se analiza el precio/hora. Se reduce, así, a claras manifestaciones de discriminación, tanto directa como indirecta.

La segregación ocupacional es también evidente, tanto desde un punto de vista horizontal (puestos feminizados menos valorados) como vertical (menos oportunidades de ascenso para las mujeres).

Todo lo anterior tiene un importante impacto en el sistema de Seguridad Social, dadas las dificultades de acreditar una carrera de seguro para una pensión contributiva 
partiendo de semejante desigualdad. No es extraño, pues, que el perfil de beneficiario de pensiones no contributivas sea de mujer casada, frente al de hombre soltero.

Dña. Sarai Rodríguez González (Universidad de la Laguna): como decía Dña. Sarai Rodríguez al comienzo de su exposición, el sesgo discriminatorio del mercado laboral supone que el patrón contributivo del sistema se convierta en un mecanismo transmisor de desigualdades. Dicho sistema no parece mostrar sensibilidad alguna frente al coste de la maternidad, los cuidados familiares o, en general, al trabajo doméstico no remunerado de las mujeres, algo paradójico si se tiene en cuenta su importancia para el sostenimiento de la sociedad.

Para paliar esta situación, se han incorporado a nuestro ordenamiento medidas como los periodos de cotización ficticia para el caso de las excedencias por cuidado de hijos u otros familiares o la "contribución demográfica", que permite reconocer las consecuencias de la maternidad en la carrera de seguro de las mujeres, dotando de valor económico la aportación que éstas hacen en tanto futuros cotizantes. Sin embargo, estas medidas no están exentas de crítica, además de ser insuficientes: no son retroactivas, inciden especialmente en paliar las consecuencias de la excedencia en lugar de favorecer la compatibilización, olvidan el sobrecoste de las familias con hijos con discapacidad, etc.

\section{Maternidad, paternidad y prestaciones familiares frente a la situación laboral y familiar de las mujeres.}

Dña. Elisa Sierra (Universidad Pública de Navarra): la intervención de Dña. Elisa Sierra versa sobre las prestaciones por maternidad y paternidad y la mayor crítica parece centrarse en un punto concreto: la errónea configuración que se ha hecho del bien jurídico protegido a la luz de nuestras normas o, al menos, la incoherencia que se presenta entre el primero y las segundas. Así, si el bien jurídico protegido es la recuperación física de la madre tras el parto y el cuidado del hijo en los primeros meses de su vida, dejan de tener sentido cuestiones como el que la madre pueda distribuir hasta diez semanas de las dieciséis de las que dispone a su elección (incluso antes de haber nacido el bebé), los límites de edad para acceder a las prestaciones de maternidad o paternidad, o el hecho de que el periodo de paternidad conste únicamente de trece días, dificultando enormemente la corresponsabilidad.

Dña. María Gema Quintero Lima (Universidad Carlos III de Madrid): se cuestiona en esta intervención la existencia de una verdadera protección a la familia en nuestro país. ¿Cuál es realmente el rol de la familia en España? ¿y el de la mujer en la familia y en el mercado de trabajo?

Actualmente, las prestaciones familiares en sentido estricto pertenecen a la rama no contributiva. No obstante, el dato verdaderamente relevante es que se trata de prestacio- 
nes asistenciales que conllevan la carencia de un determinado nivel de ingresos, prácticamente rozando el umbral de la pobreza. Además, el sistema considera las cargas desde la perspectiva de la unidad familiar, lo que acaba desembocando en la feminización de las prestaciones por hijo a cargo.

Parece que el legislador español no ha tenido nunca demasiado claro cómo proteger a esa institución en constante transformación que es la familia y se ha quedado en pequeñas prestaciones en casos extremos.

\section{Análisis de las pensiones y la dependencia desde la perspectiva de género.}

Dña. Olympia del Águila Cazorla (Universidad Complutense de Madrid): Dña. Olympia del Águila ofrece una visión de los perjuicios que ha tenido para las mujeres el abandono de la lucha de género en materia de pensiones de jubilación tras la crisis económica.

En España, no existe un verdadero debate sobre esta temática, sino que más bien se han ido improvisando soluciones como la incorporación del factor de sostenibilidad a semejanza del modelo alemán. A estos efectos, se han de tener en cuenta las dificultades de la carrera de cotización de la mujer con respecto al hombre en España, ello en un sistema de reparto basado en la solidaridad. Habría que plantearse, pues, qué ocurriría en un sistema de redistribución capitalizado donde se refleja la capacidad de ahorro (menor en las mujeres) y la esperanza de vida (mayor). La dificultad de introducir mecanismos correctores de desigualdad en esos casos queda bien reflejada en la experiencia de América latina.

Dña. Eva María Blázquez Agudo (Universidad Carlos III de Madrid): la profesora Blázquez plantea una cuestión que a primera vista puede resultar controvertida: la eliminación de la pensión de viudedad, una prestación claramente feminizada.

La justificación reside en que, si la mujer continúa su progresiva incorporación al mercado laboral, habrá más pensiones de jubilación de las mujeres (que viven más años) y se generarán más pensiones de viudedad para los hombres. Lo esperable es, pues, que se llegue a una situación de incompatibilidad en la que no tenga sentido una pensión de viudedad si se tiene una propia, abandonando así los derechos derivados.

Esta medida habría de venir acompañada de otras para evitar la desprotección de ciertos colectivos, como un aumento de la pensión de orfandad o una renta mínima para todos los ciudadanos.

\section{Desempleo y políticas de integración laboral de la mujer.}

D. Daniel Pérez del Prado (Universidad Carlos III de Madrid): se trata el tema de las políticas de empleo en relación con el género, destacando el dato de las diferencias en el paro de hombres y mujeres, en perjuicio de éstas. Para solucionar este problema, se 
dispone tanto de herramientas activas de protección social, como de herramientas pasivas de creación de empleo.

Destaca el ponente un inconveniente, y es la dificultad que surge en las políticas económicas de empleo para adoptar un enfoque de género. Frente a esto, la Ley de Empleo sitúa a las mujeres como uno de los principales colectivos que necesitan ser integrados, pero ello no parece coherente con las numerosas reformas de los últimos años. No se han hecho inversiones adecuadas y la mayoría han desembocado en incentivos, que no crean empleo. Con la reforma de 2012 se produjo una modificación del sistema de incentivos, pero fue para favorecer el apoyo a emprendedores, continuando olvidado el fomento de la igualdad de género.

D. Borja Suárez (Universidad Autónoma de Madrid): expone el profesor Suárez cómo la peor protección por desempleo de las mujeres no se debe únicamente a su peor situación en el mercado de trabajo, sino también a la propia configuración del sistema de protección por desempleo, sesgado estructuralmente.

Las carreras de cotización "típicas” (las masculinizadas) reciben un tratamiento más favorable debido a la naturaleza esencialmente contributiva del sistema, las mujeres presentan mayor vulnerabilidad al despido, las empleadas del hogar continúan desprotegidas y sin ver sus sacrificios reconocidos. Por otro lado, la crisis ha provocado un agotamiento del sistema a raíz del paro de larga duración y la "vuelta a la normalidad" tras la caída de sectores masculinizados ha dejado ver una disminución de cobertura, un menor número de mujeres perceptoras del desempleo y un mayor número de desempleadas que no reciben prestación.

Se pone fin, con ello, a esta Jornada sobre Género y Seguridad Social, clausurada por Dña. Rosa San Segundo Manuel, directora del Instituto de Estudios de Género de la Carlos III. Termina compartiendo el deseo y la necesidad de implantar una verdadera educación por la igualdad en la enseñanza universitaria, un objetivo que, como tantos otros, ha quedado en la sombra con el paso de la crisis económica. 